\title{
Safety, Tolerability and Pharmacokinetics of L-Ornithine Phenylacetate in Patients with Acute Liver Injury/Failure and Hyperammonemia.
}

R. Todd Stravitz ${ }^{1}$, Michelle Gottfried ${ }^{2}$, Valerie Durkalski ${ }^{2}$, Robert J. Fontana ${ }^{3}$, A. James Hanje ${ }^{4}$, David Koch $^{2}$, Bilal Hameed ${ }^{5}$, Daniel Ganger ${ }^{6}$, Ram M. Subramanian ${ }^{7}$, Stan Bukofzer ${ }^{8}$, William R. Ravis ${ }^{9}, K_{\text {risten Clasen }}^{2}$, Averell Sherker ${ }^{10}$, Lanna Little ${ }^{11}$, and William M. Lee ${ }^{11}$, for the Acute Liver Failure Study Group.

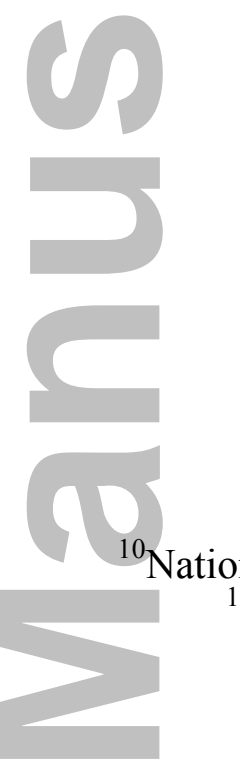

\author{
${ }^{1}$ Virginia Commonwealth University, Richmond, VA \\ ${ }^{2}$ Medical University of South Carolina, Charleston, SC \\ ${ }^{3}$ University of Michigan, Ann Arbor, MI \\ ${ }^{4}$ Ohio State University, Columbus, $\mathrm{OH}$
}

${ }^{5}$ University of California at San Francisco, San Francisco, CA

${ }^{6}$ Northwestern University, Chicago, IL

${ }^{7}$ Emory University, Atlanta, GA

${ }^{8}$ Ocera Therapeutics, Durham, NC

${ }^{9}$ Auburn University, Tuscaloosa, AL

National Institute of Diabetes, Digestive and Kidney Disease, Bethesda, MD

${ }^{11}$ University of Texas, Southwestern Medical Center, Dallas, TX.

Key words: cerebral edema, ammonia, hepatic encephalopathy, intracranial hypertension, acetaminophen.

This is the author manuscript accepted for publication and has undergone full peer review but has not been through the copyediting, typesetting, pagination and proofreading process, which may lead to differences between this version and the Version of record. Please cite this article as doi:10.1002/ hep.29621. 
Address Correspondence:

R. Todd Stravitz, MD

Professor of Medicine

Medical Director of Liver Transplantation

Hume-Lee Transplant Center of

Virginia Commonwealth University

PO Box 980341

Richmond, VA 23298-0341

Tel 804 828-8514

Fax 804 828-4945

Richard.Stravitz@VCUHealth.ORG

\section{Abbreviations.}

ALF, acute liver failure

ALI, acute liver injury

APAP, acetaminophen

AUC, area-under-the-curve

CRRT, continuous renal replacement therapy

ECG, electrocardiogram

GLN, glutamine

GLU, glutamate

HE, hepatic encephalopathy

$\mathrm{IQR}$, interquartile range

LT, liver transplantation

LOLA, L-ornithine, L-aspartate

MOSF, multi-organ system failure

PA, phenylacetate

PAGN, phenylacetylglutamine

PK, pharmacokinetic(s)

ORN, ornithine

OPA, L-ornithine phenylacetate

SRC, Safety Review Committee

SS, spontaneous survival

UPLC, ultra-performance liquid chromatography

Financial Support: Supported by NIDDK U-01 58369. Study drug and pharmacokinetic analysis were supplied by Ocera Therapeutics, Inc. 
Cerebral edema remains a significant cause of morbidity and mortality in patients with acute liver failure (ALF) and has been linked to elevated blood ammonia levels. L-ornithine phenylacetate (OPA) may decrease ammonia by promoting its renal excretion as phenylacetylglutamine (PAGN), decreasing the risk of cerebral edema. We evaluated the safety, tolerability, and pharmacokinetics of OPA in patients with ALF and acute liver injury (ALI), including those with renal failure. Forty-seven patients with $\mathrm{ALI} / \mathrm{ALF}$ and ammonia $\geq 60 \mu \mathrm{M}$ were enrolled. Patients received OPA in a dose escalation scheme from $3.3 \mathrm{~g} / 24 \mathrm{~h}$ to $10 \mathrm{~g} / 24 \mathrm{~h} ; 15$ patients received $20 \mathrm{~g} / 24 \mathrm{~h}$ throughout the infusion for up to $120 \mathrm{~h}$. Plasma phenylacetate concentrations [PA] were uniformly below-target $(<75 \mu \mathrm{g} / \mathrm{ml})$ in those receiving $3.3 \mathrm{~g} / 24 \mathrm{~h}$ (median[IQR] 5.0[5.0] $\mu \mathrm{g} / \mathrm{ml}$ ), and increased to target levels in all but one who received $20 \mathrm{~g} / 24 \mathrm{~h}$ $(150[100] \mu \mathrm{g} / \mathrm{ml})$. Plasma $[\mathrm{PAGN}]$ increased, and conversion of PA to PAGN became saturated, with increasing OPA dose. Urinary PAGN clearance and creatinine clearance were linearly related $(\mathrm{r}=0.831, \mathrm{P}<0.0001)$. Mean ammonia concentrations based on the area-under-the-curve decreased to a greater extent in patients who received $20 \mathrm{~g} / 24 \mathrm{~h}$ OPA compared to those who received the 3.3 or $6.7 \mathrm{~g} / 24 \mathrm{~h}$ maximal dose $(\mathrm{P}=0.046$ and 0.022 , respectively). Of the reported serious adverse events (AEs) including 11 deaths, none were attributable to study medication. The only non-serious AEs possibly related to study drug were headache and nausea/vomiting. Conclusions. OPA was well-tolerated in patients with ALI/ALF, and no safety signals were identified. Target [PA] was achieved at infusion rates of $20 \mathrm{~g} / 24 \mathrm{~h}$, leading to ammonia excretion in urine as PAGN in proportion to renal function. Randomized, controlled studies of high-dose OPA are needed to determine its utility as an ammonia-scavenging agent in patients with ALF. 
The syndrome of acute liver failure (ALF) evolves rapidly from primary liver injury to secondary multi-organ system failure (MOSF), and results in death or the need for liver transplantation (LT) in more than half of affected patients(1). The risk of developing cerebral edema, a systemic complication of ALF which dramatically increases the incidence of poor outcome(2), is directly proportional to blood ammonia concentrations(3).

In healthy patients, ammonia produced in the gut is bio-transformed into urea and eliminated in urine. In patients with ALF, however, ammonia accumulates in the blood due to deficient activity of hepatic urea cycle enzymes. In the brain, ammonia is taken up by astrocytes and detoxified by glutamine synthetase into glutamine (GLN), an osmotically-active molecule(4). The rapid accumulation of GLN in the brain of patients with ALF is believed to overwhelm compensatory mechanisms which shed intracellular osmolytes, creating an osmotic gradient that results in astrocyte swelling, an increase in brain volume, and intracranial hypertension. Sustained astrocyte swelling can become unresponsive to medical therapy with osmotic agents such as mannitol or hypertonic saline, resulting in uncal herniation and death. Therefore, a strong rationale exists for ammonia-lowering therapies to treat hyperammonemia and prevent cerebral edema in patients with ALF.

Effective ammonia-lowering agents have been developed for infants and children with inborn errors of urea cycle enzymes(5). Ammonia-lowering agents have received comparatively little study in adults with acute or chronic liver disease. L-ornithine L-aspartate (LOLA) is a compound hypothesized to lower ammonia by providing a precursor for glutamate synthesis (ornithine [ORN]), which serves to bind ammonia to form GLN. Unfortunately, a large, randomized, placebo-controlled study of LOLA in adults with ALF (6) failed to lower blood ammonia levels or improve survival. Jalan and Lee have hypothesized the lack of efficacy of 
LOLA in ALF may be due to the deamidation of GLN by glutaminases in the gut and other tissues, thereby liberating ammonia back into the circulation(7).

Other ammonia-lowering agents have been developed to prevent the deamidation of GLN. Phenylacetate (PA) promotes renal excretion of glutamine and has been used for this purpose in children with urea cycle defects(8). L-ornithine phenylacetate (OPA), a salt which provides both a substrate for the synthesis of glutamine, ORN, as well as a GLN-scavenging agent, $\mathrm{PA}$, is hypothesized to promote the renal excretion of phenylacetylglutamine (PAGN) (Supplemental Figure 1)(9). Studies in rat (10) and pig (11) models of ALF have documented a reduction of blood ammonia during OPA infusion and proved the ability of this compound to act as an effective ammonia scavenger. However, the safety of this compound in humans remains somewhat uncertain considering that astrocyte mitochondria in experimental animals express glutaminases, which have the potential to deamidate GLN and release ammonia, theoretically increasing neurotoxicity(12).

Previous studies have suggested that OPA is, in fact, safe and well-tolerated in patients with cirrhosis, and have demonstrated its ability to promote nitrogen excretion in urine as PAGN $(13,14)$. The present exploratory study is the first to test the safety and tolerability of escalating doses of OPA in humans with acute liver injury (ALI; no encephalopathy) and ALF, who often have dramatically higher serum ammonia levels than do patients with cirrhosis. Secondary objectives included the evaluation of the pharmacokinetic (PK) and pharmacodynamics of OPA in hyperammonemic patients with ALI/ALF. 


\section{Patients and Methods.}

Since its founding in 1998, more than 3,000 adult patients have been enrolled in the ALF Study Group Registry wherein detailed data and daily bio-samples are collected over 7 days. All study patients met criteria for ALF or ALI for the Registry, as defined previously(1, 15). Consent was provided by the patient if there were no evident hepatic encephalopathy (ALI), and the patients' legal next of kin, if the patient exhibited signs of encephalopathy (ALF). Separate consents were obtained for the Registry and the OPA clinical trial. The study was approved by each institution's Internal Review Board, conforming to the ethical guidelines of the 1975 Declaration of Helsinki.

The primary objective of the study was to evaluate the safety and tolerability of ascending doses of OPA in patients with ALF and severe ALI with and without renal impairment. Secondary objectives included the evaluation of the PK and pharmacodynamic profile of OPA in patients with ALI/ALF. Exploratory objectives included the evaluation of the effects of OPA on serum ammonia.

Study Population. The study was conducted at 8 US liver transplant centers which have demonstrated high-volume enrollment in the ALF Study Group Registry. A total of 301 patients were screened to achieve enrollment of 47 patients meeting all criteria (Supplemental Figure 2). Inclusion criteria included age 18-65 years, with ALI or ALF as defined, and a plasma ammonia of $\geq 60 \mu \mathrm{M}$ within 8 hours of the initiation of OPA infusion (defined as Time 0). Exclusion criteria included a history of chronic liver disease, signs of overt uncal herniation or uncontrolled intracranial hypertension, significant gastrointestinal bleeding, hemodynamic instability defined by a mean arterial pressure of $<65 \mathrm{mmHg}$ after volume resuscitation, $\mathrm{QT}_{\mathrm{c}}$ interval on baseline ECG of $>500 \mathrm{msec}$, or a history of heart failure, pulmonary hypertension, or concomitant 
medications known to interfere with renal excretion of PAGN (haloperidol, valproic acid, and others). Patients with ALI/ALF from pregnancy (acute fatty liver of pregnancy and the hemolysis-elevated liver chemistry-low platelet syndrome), acute Wilson Disease, malignancy and shock/ischemia were also excluded from participation. Lactulose and/or rifaximin were not permitted during the study period. Entry criteria were broadened during the study as early safety and tolerability assessments found no safety signals. Initially, enrollment was limited to patients with acetaminophen (APAP)-induced ALI/ALF because these patients are most likely to develop cerebral edema. Other etiologies were later admitted to the study as long as subjects met the baseline ammonia criterion of $\geq 60 \mu \mathrm{M}$.

Data on safety and tolerability were collected from all 47 patients. In order to assess the efficacy of ammonia-lowering, patients were considered evaluable if they received at least $72 \mathrm{~h}$ of OPA infusion, as defined a priori. Eleven patients failed to meet the $72 \mathrm{~h}$ infusion criterion and were thus excluded from the ammonia assessment, but were included in pharmacokinetic (PK) assessment. Three of the 47 patients had no plasma samples available for determination of PK because they were removed from the study shortly after enrollment (one patient died, one was transplanted, and one withdrew consent/signed out against medical advice).

Study drug infusion scheme. OPA infusions were first administered to patients with relatively normal renal function (defined as a baseline serum creatinine $\leq 1.5 \mathrm{mg} / \mathrm{dl}$ ), and later, after clearance by a Safety Review Committee (SRC), to patients with impaired renal function (defined as serum creatinine $>1.5 \mathrm{mg} / \mathrm{dl}$ ). For safety, OPA infusion doses were administered incrementally, starting at $3.3 \mathrm{~g} / 24 \mathrm{~h}$ as a constant intravenous infusion. Preliminary studies showed that OPA and $N$-acetylcysteine (NAC) were compatible for infusion through the same intravenous line, and were well-tolerated through peripheral or central venous infusion. Three 
evaluable patients were enrolled at each dose level before beginning enrollment in the next dose level.

The dose escalation scheme is depicted in Figure 1. The beginning of OPA infusion was defined as Time 0 . The first patient cohort received OPA $3.3 \mathrm{~g} / 24 \mathrm{~h}$ for up to $120 \mathrm{~h}$. After safety and tolerability were assessed by the SRC, the second group received $3.3 \mathrm{~g} / 24 \mathrm{~h}$ for $12 \mathrm{~h}$, then increased to $6.7 \mathrm{~g} / 24 \mathrm{~h}$ for the remainder of the infusion if there were no safety signals as assessed by the site clinical investigator. The third cohort received the initial $3.3 \mathrm{~g} / 24 \mathrm{~h}$, the $6.7 \mathrm{~g} / 24 \mathrm{~h}$ dose for the subsequent $12 \mathrm{~h}$, and then $10 \mathrm{~g} / 24 \mathrm{~h}$ for the remainder of the infusion, again, assuming there were no safety signals. Finally, since OPA infusions including the $10 \mathrm{~g} / 24 \mathrm{~h}$ dose were deemed safe and well-tolerated by the SRC, a final cohort received a constant infusion of $20 \mathrm{~g} / 24 \mathrm{~h}$ for up to $120 \mathrm{~h}$. Some subjects received fewer than $120 \mathrm{~h}$ infusion because the patient expired, was transplanted, withdrew consent, or improved and was discharged.

Clinical Evaluation. A complete physical exam, laboratory studies including ammonia, plasma and urine sampling for PK studies, and a safety assessment including ECG for $\mathrm{QT}_{\mathrm{c}}$ interval was performed during OPA infusion every $12 \mathrm{~h}$ for the first 3 days and every $24 \mathrm{~h}$ thereafter. Clinical evaluations included neurological assessment including recording of the hepatic encephalopathy grade according to West Haven Criteria, plasma ammonia, creatinine and other standard laboratory tests, and urinalysis. All evaluations and samples were also collected at completion of the OPA infusion, and $24 \mathrm{~h}$ following the completion of the infusion.

Laboratory Methods. PK studies were performed on plasma from blood samples drawn into EDTA-containing Vacutainers. Plasma samples for ammonia were collected in heparinized Vacutainer tubes and transported to the laboratory on ice. Samples were run for ammonia according to local protocol. Plasma PA/PAGN/ORN levels were determined using an ultra- 
performance liquid chromatography (UPLC) method with tandem mass spectrometric detection. The concentration range for all analytes was 5 to $1000 \mu \mathrm{g} / \mathrm{ml}$. Urine PAGN levels were determined using a UPLC method with tandem mass spectrometric detection. The concentration range was 300 to $200,000 \mu \mathrm{g} / \mathrm{ml}$.

Data Collection and Management. The entire study duration for each patient was approximately 32 days; screening assessment, baseline, up to 5 days of treatment, follow up assessment $24 \mathrm{~h}$ after completion of the last infusion, and a post-treatment visit approximately 30 days after treatment day 1 unless terminated early from the trial.

Average plasma concentrations of ORN, PA, and PAGN during the infusions were obtained from the area under the curve (AUC) vs. time from 2-3 days until the end of the infusions, divided by the time period of infusion. Estimates of PAGN renal clearance were calculated by dividing the average daily excretion rate of PAGN by the average PAGN plasma concentration during the same period for each subject. To evaluate drug effects on blood ammonia concentrations, values for the percent decrease from Time 0 were calculated for each sampling time. The average percent decrease in ammonia concentration from $0-72 \mathrm{~h}$ and from 0 120h were then determined from the AUC for the percent decrease vs. time, divided by the infusion time of OPA.

Data on clinical outcomes were also collected during the study period. All data were collected and reviewed on a secure central server at the Medical University of South Carolina's Data Coordination Unit, which serves as the data coordinating center for the ALF Study Group. Data were assessed through statistical and data management checks to ensure quality and verification. 
Statistical Analysis. All statistical analyses were performed using SAS version 9.4 (SAS Institute, Cary, NC). Missing values were not replaced or estimated. Descriptive statistics characterized the demographics and other clinical variables. Categorical variables were compared using the Chi-square test, or Fisher's exact test (when expected cell counts were $<5$ ). Medians were reported with interquartile ranges (IQR) and compared using the Wilcoxon rank sum test. Plasma concentration results were compared by ANOVA methods of log-transformed or rank values. The relationship between baseline creatinine and PK variables were examined with descriptive statistics.

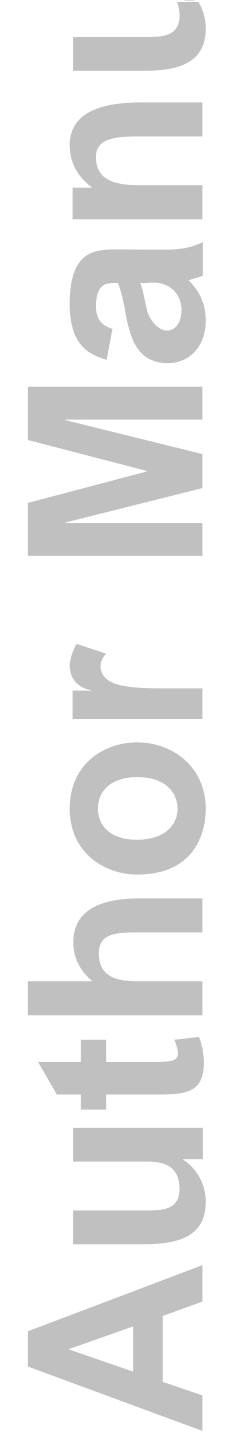




\section{Results. \\ Study population characteristics.}

Forty-seven patients with ALI/ALF were enrolled into the study, 36 of whom were predefined as evaluable (OPA infusion $\geq 72 \mathrm{~h}$ ) for measurement of ammonia-lowering efficacy (Table 1). The normal renal function cohort (serum creatinine at screening of $\leq 1.5 \mathrm{mg} / \mathrm{dl}$ $[\mathrm{N}=30]$ ) differed significantly from the impaired renal function cohort (creatinine $>1.5 \mathrm{mg} / \mathrm{dl}$ $[\mathrm{N}=17])$ by percent female gender (80 vs. $41 \%$, respectively), the proportion with acetaminophen (APAP) overdose as the etiology (83vs. 41\%), and by definition, median serum creatinine $(0.7$ vs. $2.5 \mathrm{mg} / \mathrm{dl})$, and percent on continuous renal replacement therapy (CRRT; 3.3 vs. $59 \%$, respectively).

Plasma concentrations of study drug components and product at steady-state.

PK assessments included data from 44 of the 47 enrollments. Some of the 8 patients who received the lowest dose of OPA $(3.3 \mathrm{~g} / 24 \mathrm{~h})$ had undetectably low plasma ORN, PA, and/or PAGN, and were thus omitted from the analyses in Figure 2, which depict plasma concentrations at steady-state according to maximal infusion rate of OPA. Plasma [ORN] at steady-state (Figure 2A) was neither related to the infusion rate of OPA nor affected by renal impairment. There was no relationship of plasma $[\mathrm{ORN}]$ to serum creatinine in patients who received the $6.7,10$, or $20 \mathrm{~g} / 24 \mathrm{~h}$ infusion rate of OPA $(\mathrm{P}=0.76,0.52$, and 0.79 , respectively [data not shown]). In contrast, mean plasma [PA] (Figure 2B) increased with the infusion rate of OPA, although was not significantly different in patients with normal and impaired renal function. There was no relationship between $[\mathrm{PA}]$ and creatinine concentrations in patients who received the $6.7,10$, and $20 \mathrm{~g} / 24 \mathrm{~h}$ infusion rate $(\mathrm{P}=0.10,0.38$, and 0.71 , respectively [data not 
shown]). Plasma [PAGN] increased not only with increasing OPA infusion rate but also in patients with renal impairment, compared to those with normal renal function (Figure 2C). Excretion of PAGN.

Figure 3 depicts the relationship of plasma [PAGN] and urinary PAGN excretion to renal function at baseline. As shown in Figure 3A, plasma [PAGN] increased as a function of baseline creatinine for the $6.7 \mathrm{~g} / 24 \mathrm{~h}$ infusion rate $(\mathrm{P}=0.015)$, the $10 \mathrm{~g} / 24 \mathrm{~h}$ rate $(\mathrm{P}=0.003)$, and the $20 \mathrm{~g} / 24 \mathrm{~h}$ rate $(\mathrm{P}<0.001)$. Moreover, renal PAGN clearance was linearly related to creatinine clearance with a slope of $1.18(\mathrm{r}=0.831 ; \mathrm{P}<0.0001$ [Figure 3B]). Renal clearance of PAGN was inversely related to plasma [PAGN] (Figure 3C), consistent with renal tubular secretion. The inverse relationship was stronger in patients with normal renal function $(\mathrm{P}<0.001)$ than with impaired renal function $(\mathrm{P}=0.002)$.

Eleven patients were treated with CRRT during OPA infusion. Samples of dialysate were also analyzed for PAGN. PAGN concentrations in dialysate were below the limit of detection in all samples.

\section{Effects of OPA on serum ammonia concentrations.}

The current Phase 2a study was not designed to assess the efficacy of OPA in ammonialowering nor improvement in grade of HE. Nevertheless, detailed information on ammonia concentrations and HE grade was collected during the study period and follow-up. Ammonia concentrations varied greatly between patients as well as within patients over time. In 5 study patients, all of whom died, ammonia inexorably increased during OPA infusion. Three of these 5 patients received the $3.3 \mathrm{~g} / 24 \mathrm{~h}$ OPA dose, and died of cerebral edema $(\mathrm{N}=1)$ and multi-organ system failure (MOSF) $(\mathrm{N}=2)$. The others $(\mathrm{N}=1 \mathrm{each})$ received $10 \mathrm{~g} / 24 \mathrm{~h}$ and $20 \mathrm{~g} / 24 \mathrm{~h}$, and died of MOSF and septic shock, respectively. Although 2 of the 5 patients received OPA for $\geq 72 \mathrm{~h}$ and 
were considered evaluable in the ammonia-lowering efficacy study, they were hemodynamically unstable and pre-terminal. Thus, the exploratory analysis of OPA on ammonia-lowering was based upon 34 patients, the 36 who received study drug for $\geq 72 \mathrm{~h}$ excluding the 2 evaluable but pre-terminal patients with hemodynamic collapse, a condition which could not support effective ammonia-lowering by OPA.

The distribution of hepatic encephalopathy grades (by West Haven criteria(16)) and respective serum ammonia for each grade at Time 0 is shown in Figure 4. Of the entire 47 patient cohort, 16 had no HE (ALI), while grade 1,2,3, and $4 \mathrm{HE}$ was recorded in 8,8,4, and 11 patients, respectively. The patients with HE grades 0-3 all had elevated blood ammonia levels with medians between 84 and $93 \mu \mathrm{M}$, whereas the patients with grade 4 coma had significantly higher median ammonia than lower grades $(137 \mu \mathrm{M})$. Figure 5 depicts the average percent lowering of plasma ammonia based on AUC over two time periods, $0-72 \mathrm{~h}(\mathrm{~N}=34$ patients) and 0$120 \mathrm{~h}(\mathrm{~N}=29$ patients). For patients with data available between $0-72 \mathrm{~h}$, the percent decrease in ammonia AUC concentrations in patients receiving $20 \mathrm{~g} / 24 \mathrm{~h}$ was larger than in patients who received 3.3 or $6.7 \mathrm{~g} / 24 \mathrm{~h}(\mathrm{P}=0.048$ and 0.030 , respectively). For patients with data available between $0-120 \mathrm{~h}$, the percent decrease in ammonia AUC concentrations in those receiving $20 \mathrm{~g} / 24 \mathrm{~h}$ was significantly higher than those who received 3.3 or $6.7 \mathrm{~g} / 24 \mathrm{~h}(\mathrm{P}=0.046$ and 0.022 , respectively). We performed a 2-factor analysis examining a possible confounding effect of CRRT on ammonia-lowering by OPA. For the patients with $0-72 \mathrm{~h}$ and $0-120 \mathrm{~h}$ ammonia AUC data, RRT had no discernable effect on the decrease in ammonia AUC concentrations ( $\mathrm{P}=0.346$ and 0.226 , respectively; data not shown). Since most subjects enrolled in the study had no or low-grade (grade 1-2) $\mathrm{HE}$ at baseline ( $\mathrm{N}=32$ ), it was not possible to assess the effects of OPA on HE grade. 
Safety and tolerability of OPA in patients with ALI/ALF.

Adverse events (AEs) and their relatedness to the study drug are depicted in Table 2 for all 47 patients. All reported AEs classified by MedDRA Term are depicted in Supplemental Table 1 according to OPA infusion dose. AEs were expected in this trial because of the severity and global systemic effects of liver failure in patients with the ALF syndrome. Generally, OPA was safe and well-tolerated. Of a total of 107 AEs, 96 (90\%) were deemed not related, or unlikely to be related, to the study drug by the site clinical investigator. Similarly, $92(86 \%)$ were deemed non-life-threatening. All of the 26 severe, life-threatening, or fatal AEs were deemed not related, or unlikely to be related, to the study drug. AEs considered possibly related to the study drug by the site clinical investigators included abdominal pain, hypotension, nausea, pyrexia, thrombocytopenia, and vomiting. Six of these cases were deemed mild and two moderate, in severity. AEs considered probably related to the study drug included nausea, vomiting, and headache, two of which were mild, and one moderate, in severity.

The toxicity of OPA has been ascribed to plasma [PA], levels of which are associated with neurologic AEs when $\geq 500 \mu \mathrm{g} / \mathrm{ml}(17,18)$. Neurologic AEs ascribed to PA have included nausea, vomiting, headache, dizziness, lethargy, somnolence, confusion, and dysgeusia. Since the definition of the ALF syndrome includes altered sensorium and mentation, lethargy, somnolence and confusion were not specifically captured as AEs. There were 7 patients who experienced 8 neurologic AEs (nausea 1, headache 4 and vomiting 3). One patient had two reported AEs of vomiting. The median plasma [PA] in 6 of 7 patients with neurologic AEs ([PA] was not available in 1 patient) was 16.0 (range 5.0-168.0) $\mu \mathrm{g} / \mathrm{ml}$, compared to 43.7 (range 2.5490) $\mu \mathrm{g} / \mathrm{ml}$ in patients without neurologic AEs (Wilcoxon P-value of 0.388). 
Since biotransformation of PA to PAGN largely occurs in the liver, a plasma PA/PAGN ratio $>2.5$, reflecting hepatic dysfunction, has been suggested to predict high plasma [PA], and an increased likelihood of neurologic AEs in patients with cirrhosis(8). However, despite plasma $\mathrm{PA} / \mathrm{PAGN}$ ratios frequently $>2.5$ in patients with ALI/ALF, the highest plasma AUC [PA] in any patient regardless of OPA dose or renal dysfunction was $326 \mu \mathrm{g} / \mathrm{ml}$ (Supplemental Figure 3), well below the reported neurotoxic threshold.

ECG's from 16 patients were electronically flagged by the ECG software as having $\mathrm{QT}_{\mathrm{c}}$ interval $>500 \mathrm{msec}$ during study drug infusion. In all but 3 cases, the flagged $\mathrm{QT}_{\mathrm{c}}$ was found to be inaccurate when reviewed manually by a cardiologist. In these 3 cases, a more plausible alternative etiology was identified, including severe electrolyte derangement and pericarditis.

\section{Discussion.}

The incidence of cerebral edema in patients with ALF appears to have decreased in recent years due to improvements in general intensive care and preventative measures $(19,20)$. Once established, however, cerebral edema remains one of the most highly mortal systemic complications of ALF(2). Non-specific medical therapies such as hypertonic saline and mannitol infusions merely provide temporary relief of cerebral edema because they treat the osmotic gradient driving water into astrocytes rather than treating the primary stimulus of the osmotic gradient, hyperammonemia.

In the present study of patients with ALI/ALF, PK data support the two mechanisms of action proposed for the ammonia-scavenging activity of OPA: provision of a substrate for glutamate production (ORN) and an agent to prevent the deamidation of glutamine and promote its renal excretion (PA). Plasma concentrations of ORN were not proportional to the dose of OPA, probably reflecting its rapid conversion to glutamate, suggesting that this step is not rate- 
determining. The renal clearance of PAGN was strongly correlated with creatinine clearance yet inversely proportional to plasma $[\mathrm{PAGN}]$, suggesting that the rate-limiting step in ammonia elimination may be renal tubular secretion of PAGN. Although the primary site of synthesis of PAGN from PA and GLN is the liver(21), we found no relationship between [PAGN] or the PA/PAGN ratio and the severity of primary liver injury estimated by the INR (data not shown). This observation suggests that OPA should be effective as an ammonia scavenger regardless of the severity of liver injury in patients with ALF, and is consistent with previous studies reporting similar PAGN renal excretion in healthy volunteers and patients with cirrhosis and normal renal function regardless of Child-Pugh class(22). However, since the biotransformation of PA to PAGN appears to become saturated at higher doses of OPA, the efficiency of ammonia lowering may be compromised by more severe liver failure.

The ability of CRRT to eliminate PAGN in patients with renal failure remains unproven from this study, since [PAGN] in all samples of dialysate was below the limit of detection. Although a previous report suggests that PAGN is dialyzable in renal failure patients(23), the volume of dialysate collected in the present study was inadequate to attempt re-quantitation on a concentrated sample. However, PK data from one study participant indirectly suggests that CRRT can clear PAGN. The patient, a 33 year-old male with adult Reye's Syndrome and oliguric renal failure, had the highest blood ammonia of the entire cohort $(733 \mu \mathrm{M}$ on screening and $714 \mu \mathrm{M}$ at Time 0 ), and received the highest dose of OPA (20g/24h) promptly after admission (Supplemental Figure 4). At 24h of OPA infusion, CRRT was started, and serum ammonia concentrations decreased progressively to 59 and $30 \mu \mathrm{M}$ at 72 and $96 \mathrm{~h}$ of infusion, respectively. Although PAGN was not detected in the patient's dialysate, plasma [PAGN] at steady-state reached only $111 \mu \mathrm{g} / \mathrm{ml}$, a level exceeded by 7 other patients in the cohort, 4 of 
whom were not receiving CRRT. These observations suggest that CRRT may clear PAGN because plasma PAGN did not rise to very high concentrations despite profound hyperammonemia, and the patient never developed HE or cerebral edema.

A threshold plasma [PA] to effect ammonia elimination has not been systematically defined. However, based upon a study in patients with cirrhosis who received OPA doses of $10 \mathrm{~g} / 24 \mathrm{~h}$, the maximal plasma [PA] of $25 \mu \mathrm{g} / \mathrm{ml}$ was invoked as the reason for a lack of effective ammonia-lowering(14), compared to other studies exploring the administration of glycerol phenylbutyrate $([\mathrm{PA}] 84-292 \mu \mathrm{g} / \mathrm{ml})$ and sodium phenylacetate $([\mathrm{PA}]>120 \mu \mathrm{g} / \mathrm{ml})(24)$, which were highly effective. We informally chose a plasma [PA] of $\geq 75 \mu \mathrm{g} / \mathrm{ml}$ a priori as a target level in the present study based upon these observations. Thus, many of our patients who received lower doses of OPA did not reach target plasma [PA]. In fact, only patients who received the $20 \mathrm{~g} / 24 \mathrm{~h}$ dose reliably reached plasma [PA] of $75 \mu \mathrm{g} / \mathrm{ml}$; none of those who received $3.3 \mathrm{~g} / 24 \mathrm{~h}$ met target, whereas only one patient who received $20 \mathrm{~g} / 24 \mathrm{~h}$ failed to reach target. Although previous studies of PA as a chemotherapeutic agent reported a neurotoxic threshold of PA of $>500 \mu \mathrm{g} / \mathrm{ml}(17,18)$, this level was not approached in any patient with ALI/ALF receiving the $20 \mathrm{~g} / 24 \mathrm{~h}$ infusion regardless of renal failure or PA/PAGN ratio (Supplemental Figure 3). Therefore, these data suggest that a dose of $20 \mathrm{~g} / 24 \mathrm{~h}$ may be optimal for patients with ALI/ALF.

The current study indicates that OPA is both safe and well-tolerated in patients with ALI/ALF. Only a minority of AEs were deemed possibly related to study drug, and all were non-life-threatening. Those AEs probably related to study drug included nausea, vomiting, and headache, all of which were graded non-serious by the site clinical investigator, and easily could be ascribed to the illness rather than the treatment. These AEs have been described in normal healthy volunteers treated with glycerol phenylbutyrate (a precursor of PA) as a function of 
increasing [PA], but resolved with continued dosing(8). However, we caution that most of the patients in the current study had altered mentation and may have under-reported these potential neurologic AEs. In addition, AEs ascribed to [PA] in previous studies also included confusion, lethargy, and somnolence(18), which would have been impossible to accurately distinguish from symptoms of severe liver injury in our patient population.

Although the current phase 2a study was not designed to assess the efficacy of OPA to lower ammonia in patients with ALI/ALF, the data suggest that OPA may be effective as an ammonia scavenger. Indeed, there was evidence of a dose-dependent decrease in average ammonia AUC concentrations between $0-72 \mathrm{~h}$ and $0-120 \mathrm{~h}$ of OPA infusion in patients who received $20 \mathrm{~g} / 24 \mathrm{~h}$ compared to 3.3 or $6.7 \mathrm{~g} / 24 \mathrm{~h}$. CRRT had no discernable effect on ammonialowering by OPA, although numbers of patients who received CRRT were small. The escalating dose scheme, designed for safety, may explain the delayed effect in ammonia-lowering; the insufficient dose of OPA in patients who received $<20 \mathrm{~g} / 24 \mathrm{~h}$ also played a role. These observations require confirmation with further studies of appropriate design. The effect of OPA on clinical outcome, improvement of HE or prevention or treatment of cerebral edema, could not be assessed by the present study, and also require further study.

The ammonia-lowering data also suggest that OPA may be futile in a subset of patients who are in the process of dying. Five patients were identified with steady increases in blood ammonia despite OPA infusion, 3 of whom died of multi-organ system failure, 1 of cerebral edema, and 1 of sepsis. Such patients would not be likely to respond to OPA, since intact circulation of OPA, its constituents, and PAGN requires proper delivery to the tissues illustrated in Supplemental Figure 1. 
In summary, the current study suggests that OPA is safe and well-tolerated in patients with ALI/ALF, and supports the concept of OPA as a possible ammonia-scavenging agent by the mechanisms previously proposed(9). Although further studies are required to determine the efficacy of OPA, the preliminary data presented suggest that $20 \mathrm{~g} / 24 \mathrm{~h}$ lowers serum ammonia in patients with ALI/ALF.

\section{References.}

1. Reuben A, Tillman H, Fontana RJ, Davern T, McGuire B, Stravitz RT, et al. Outcomes in Adults With Acute Liver Failure Between 1998 and 2013: An Observational Cohort Study. Ann Intern Med 2016 Jun 7;164(11):724-732.

2. Kumar R, Shalimar, Sharma H, Prakash S, Panda SK, Khanal S, et al. Persistent hyperammonemia is associated with complications and poor outcomes in patients with acute liver failure. Clin Gastroenterol Hepatol 2012 Aug;10(8):925-931.

3. Bernal W, Hall C, Karvellas CJ, Auzinger G, Sizer E, Wendon J. Arterial ammonia and clinical risk factors for encephalopathy and intracranial hypertension in acute liver failure. Hepatology 2007 Dec;46(6):1844-1852.

4. Mpabanzi L, Jalan R. Neurological complications of acute liver failure: pathophysiological basis of current management and emerging therapies. Neurochem Int 2012 Jun;60(7):736-742.

5. Enns GM, Berry SA, Berry GT, Rhead WJ, Brusilow SW, Hamosh A. Survival after treatment with phenylacetate and benzoate for urea-cycle disorders. N Engl J Med 2007 May 31;356(22):2282-2292.

6. Acharya SK, Bhatia V, Sreenivas V, Khanal S, Panda SK. Efficacy of L-ornithine Laspartate in acute liver failure: a double-blind, randomized, placebo-controlled study. Gastroenterology 2009 Jun;136(7):2159-2168.

7. Jalan R, Lee WM. Treatment of hyperammonemia in liver failure: a tale of two enzymes. Gastroenterology 2009 Jun;136(7):2048-2051.

8. Mokhtarani M, Diaz GA, Rhead W, Berry SA, Lichter-Konecki U, Feigenbaum A, et al. Elevated phenylacetic acid levels do not correlate with adverse events in patients with urea cycle disorders or hepatic encephalopathy and can be predicted based on the plasma PAA to PAGN ratio. Mol Genet Metab 2013 Dec;110(4):446-453. 
9. Jalan R, Wright G, Davies NA, Hodges SJ. L-Ornithine phenylacetate (OP): a novel treatment for hyperammonemia and hepatic encephalopathy. Med Hypotheses 2007;69(5):1064-1069.

10. Davies NA, Wright G, Ytrebo LM, Stadlbauer V, Fuskevag OM, Zwingmann C, et al. Lornithine and phenylacetate synergistically produce sustained reduction in ammonia and brain water in cirrhotic rats. Hepatology $2009 \mathrm{Jul} ; 50(1): 155-164$.

11. Ytrebo LM, Kristiansen RG, Maehre H, Fuskevag OM, Kalstad T, Revhaug A, et al. Lornithine phenylacetate attenuates increased arterial and extracellular brain ammonia and prevents intracranial hypertension in pigs with acute liver failure. Hepatology 2009 Jul;50(1):165-174.

12. Rama Rao KV, Norenberg MD. Glutamine in the pathogenesis of hepatic encephalopathy: the trojan horse hypothesis revisited. Neurochem Res 2014;39(3):593598.

13. Ventura-Cots M, Arranz JA, Simon-Talero M, Torrens M, Blanco A, Riudor E, et al. Safety of ornithine phenylacetate in cirrhotic decompensated patients: an open-label, dose-escalating, single-cohort study. J Clin Gastroenterol 2013 Nov;47(10):881-887.

14. Ventura-Cots M, Concepcion M, Arranz JA, Simon-Talero M, Torrens M, Blanco-Grau A, et al. Impact of ornithine phenylacetate (OCR-002) in lowering plasma ammonia after upper gastrointestinal bleeding in cirrhotic patients. Therap Adv Gastroenterol 2016 Nov;9(6):823-835.

15. Koch DG, Speiser JL, Durkalski V, Fontana RJ, Davern T, McGuire B, et al. The Natural History of Severe Acute Liver Injury. Am J Gastroenterol 2017 Apr 25.

16. Conn HO, Leevy CM, Vlahcevic ZR, Rodgers JB, Maddrey WC, Seeff L, et al. Comparison of lactulose and neomycin in the treatment of chronic portal-systemic encephalopathy. A double blind controlled trial. Gastroenterology 1977 Apr;72(4 Pt 1):573-583.

17. Thibault A, Cooper MR, Figg WD, Venzon DJ, Sartor AO, Tompkins AC, et al. A phase I and pharmacokinetic study of intravenous phenylacetate in patients with cancer. Cancer Res 1994 Apr 1;54(7):1690-1694.

18. Thibault A, Samid D, Cooper MR, Figg WD, Tompkins AC, Patronas N, et al. Phase I study of phenylacetate administered twice daily to patients with cancer. Cancer 1995 Jun 15;75(12):2932-2938.

19. Bernal W, Hyyrylainen A, Gera A, Audimoolam VK, McPhail MJ, Auzinger G, et al. Lessons from look-back in acute liver failure? A single centre experience of 3300 patients. J Hepatol 2013 Jul;59(1):74-80. 
20. Murphy N, Auzinger G, Bernel W, Wendon J. The effect of hypertonic sodium chloride on intracranial pressure in patients with acute liver failure. Hepatology 2004 Feb;39(2):464-470.

21. Moldave K, Meister A. Enzymic acylation of glutamine by phenylacetic acid. Biochim Biophys Acta 1957 Jun;24(3):654-655.

22. McGuire BM, Zupanets IA, Lowe ME, Xiao X, Syplyviy VA, Monteleone J, et al. Pharmacology and safety of glycerol phenylbutyrate in healthy adults and adults with cirrhosis. Hepatology 2010 Jun;51(6):2077-2085.

23. Zimmerman L, Jornvall H, Bergstrom J. Phenylacetylglutamine and hippuric acid in uremic and healthy subjects. Nephron 1990;55(3):265-271.

24. Ghabril M, Zupanets IA, Vierling J, Mantry P, Rockey D, Wolf D, et al. Glycerol Phenylbutyrate in Patients With Cirrhosis and Episodic Hepatic Encephalopathy: A Pilot Study of Safety and Effect on Venous Ammonia Concentration. Clin Pharmacol Drug Dev 2013 Jul;2(3):278-284. 


\section{Figure Legends.}

Figure 1. Ornithine phenylacetate (OPA) dose escalation scheme.

* Number of patients enrolled into each infusion cohort (total $\mathrm{N}$ and [number of patients evaluable for the ammonia efficacy assessment who received $\geq 72 \mathrm{~h}$ of OPA infusion]).

Figure 2. Plasma concentrations of ornithine (A), phenylacetate (B), and phenylacetylglutamine $(\mathrm{C})$ according to maximal infusion rate of ornithine phenylacetate in normal and renal-impaired subgroups.

Data are shown for patients with "normal" and "impaired renal function" as defined in Methods. (ORN, ornithine; PA, phenylacetate; PAGN, phenylacetylglutamine).

Figure 3. Concentration of phenylacetylglutamine (PAGN) in plasma and urine according to renal function.

(A). Plasma PAGN concentration vs. baseline serum creatinine according to maximum infusion rate of OPA. (B). PAGN renal clearance $v$ s. creatinine clearance. (C). Relationship of urinary PAGN clearance to plasma PAGN concentration. Data are shown for patients with "normal" and “impaired renal function" as defined in Methods.

(ORN, ornithine; PA, phenylacetate; PAGN, phenylacetylglutamine).

Figure 4. Plasma ammonia concentrations in the 47-patient study group by hepatic encephalopathy grade at Time 0 . The number of patients in each group according to hepatic encephalopathy grade (West Haven Scale) for grade 0 (ALI) and grades 1-4 (ALF) are: 16, $8,8,4,11$, respectively. 
Figure 5. Decrease in serum ammonia with time of OPA infusion.

Data are expressed as a percent change in average serum ammonia concentrations from time 0-

$72 \mathrm{~h}$ or $0-120 \mathrm{~h}$ according to the maximal dose of OPA infusion (mean $\pm \mathrm{SEM}$ ).

*For the AUC 0-72h, 20g/24h vs. 3.3g/24h P=0.048, and $20 \mathrm{~g} / 24 \mathrm{~h} v s .6 .7 \mathrm{~g} / 24 \mathrm{~h} \mathrm{P}=0.030$.

**For the AUC 0-120h, 20g/24h vs. $3.3 \mathrm{~g} / 24 \mathrm{~h} \mathrm{P}=0.046$, and $20 \mathrm{~g} / 24 \mathrm{~h} v s .6 .7 \mathrm{~g} / 24 \mathrm{~h} \mathrm{P}=0.022$. 


\section{Acknowledgements.}

We would like to thank Edward Doo, MD (Project Officer, NIDDK) for his tireless support of the ALF Study Group, as well as the following study coordinators: Stephanie S. Taylor, MSN, RN (Virginia Commonwealth University); Nicole O’Bleness Gray, CNP (Ohio State University); Jeanne Gottstein (Northwestern University); Melanie Crolley, RN (Medical University of South Carolina); Rivka S. Elbein, RN, BSN, CCRC (Emory University); Alina Dobai (University of California, San Francisco); Cassandra S. Coffman, BS (University of Michigan); and Deborah Rowan, LVN (University of Texas, Southwestern). We also gratefully acknowledge the contributions of Data Coordinating Center Managers Sarah Williams and Holly Tillman (Medical University of South Carolina), and Safety Review Committee Members Jorge Rakela, MD (Medical Safety Monitor and SRC Chairman; Mayo Clinic, Scottsdale), Jeffrey Browning, MD (Internal Medical Monitor; UT Southwestern Medical Center), Constantine J. (Dean) Karvellas, MD (University of Alberta, Edmonton, CA), Willis Maddrey, MD (UT Southwestern Medical Center), and Ray Chung, MD (Massachusetts General Hospital). 


\begin{tabular}{|c|c|c|c|}
\hline $\begin{array}{l}\text { Characteristic at Start of } \\
\text { OPA Infusion }\end{array}$ & $\begin{array}{c}\text { Normal Renal } \\
\text { Function } \\
\text { (Cr } \leq 1.5 \mathrm{mg} / \mathrm{dl}) \\
\mathbf{N}=\mathbf{3 0}\end{array}$ & $\begin{array}{c}\text { Impaired Renal } \\
\text { Function } \\
(\mathrm{Cr}>1.5 \mathrm{mg} / \mathrm{dl}) \\
\mathrm{N}=17\end{array}$ & p-value \\
\hline ALI $(\%)$ & 46.7 & 35.3 & 0.391 \\
\hline HE Grade $0 / 1,2 / 3,4(\%)$ & $56.6,26.7,16.7$ & $41.2,23.5,35.3$ & 0.340 \\
\hline $\mathrm{OPA} \geq 72 \mathrm{~h}(\%)$ & 76.7 & 76.4 & 0.988 \\
\hline Age (Y) & $35.0(28.0-47.0)$ & $38.0(30.0-53.0)$ & 0.319 \\
\hline Female Gender (\%) & 80.0 & 41.2 & 0.007 \\
\hline APAP (\%) & 83.3 & 41.2 & 0.003 \\
\hline ALT (IU/L) & 4305 (1562-7190) & $3695(892-6025)$ & 0.405 \\
\hline INR & $3.1(2.5-3.3)$ & $3.3(2.2-3.7)$ & 0.391 \\
\hline Bilirubin (mg/dL) & $4.0(2.8-8.0)$ & $7.5(3.4-17.6)$ & 0.095 \\
\hline Ammonia $(\mu \mathrm{M})$ & $89.0(70.0-125.0)$ & $103.0(73.0-137.0)$ & 0.775 \\
\hline Creatinine (mg/dl) & $0.7(0.5-0.9)$ & $2.5(2.0-3.80$ & $<0.0001$ \\
\hline Renal Replacement Therapy (\%) & 3.3 & 58.8 & $<0.0001$ \\
\hline
\end{tabular}

Table 1. Baseline clinical characteristics of the entire study population according to renal function cohort. (Median, range). ALT, alanine aminotransferase; APAP, acetaminophen; OPA, L-ornithine phenylacetate. 


\begin{tabular}{|c|c|c|c|c|c|c|c|c|c|c|}
\hline \multirow{3}{*}{ Severity } & \multicolumn{8}{|c|}{ Relatedness } & \multirow{2}{*}{\multicolumn{2}{|c|}{ Total }} \\
\hline & \multicolumn{2}{|c|}{ Not Related } & \multicolumn{2}{|c|}{ Unlikely } & \multicolumn{2}{|c|}{ Possibly* } & \multicolumn{2}{|c|}{ Probably** } & & \\
\hline & $\mathbf{N}$ & $\%$ & $\mathbf{N}$ & $\%$ & $\mathbf{N}$ & $\%$ & $\mathbf{N}$ & $\%$ & $\mathbf{N}$ & $\%$ \\
\hline Total & 61 & $100.0 \%$ & 35 & $100.0 \%$ & 8 & $100.0 \%$ & 3 & $100.0 \%$ & 107 & $100.0 \%$ \\
\hline Mild & 34 & $55.7 \%$ & 16 & $45.7 \%$ & 6 & $75.0 \%$ & 2 & $66.6 \%$ & 58 & $54.2 \%$ \\
\hline Moderate & 9 & $14.7 \%$ & 11 & $31.4 \%$ & 2 & $25.0 \%$ & 1 & $33.3 \%$ & 23 & $21.4 \%$ \\
\hline Severe & 5 & $8.1 \%$ & 6 & $17.1 \%$ & 0 & $0.0 \%$ & 0 & $0.0 \%$ & 11 & $10.2 \%$ \\
\hline $\begin{array}{l}\text { Life Threatening/ } \\
\text { Disabling }\end{array}$ & 2 & $3.2 \%$ & 2 & $5.7 \%$ & 0 & $0.0 \%$ & 0 & $0.0 \%$ & 4 & $3.7 \%$ \\
\hline Fatal & 11 & $18.0 \%$ & 0 & $0.0 \%$ & 0 & $0.0 \%$ & 0 & $0.0 \%$ & 11 & $10.2 \%$ \\
\hline
\end{tabular}

Table 2. Adverse events and relatedness to study drug.

*Events possibly related: abdominal pain, $\mathrm{QT}_{\mathrm{c}}$ prolongation $>500 \mathrm{msec}$ on $\mathrm{ECG}$, hypotension, nausea, pyrexia, thrombocytopenia ( 1 episode each), and vomiting (2 episodes).

**Events probably related: nausea, vomiting, headache. 


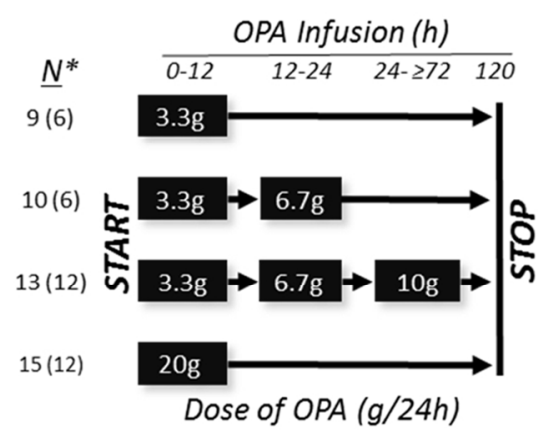

Figure 1

Figure 1 $338 \times 451 \mathrm{~mm}(96 \times 96$ DPI $)$

Hepatology

This article is protected by copyright. All rights reserved. 
A.

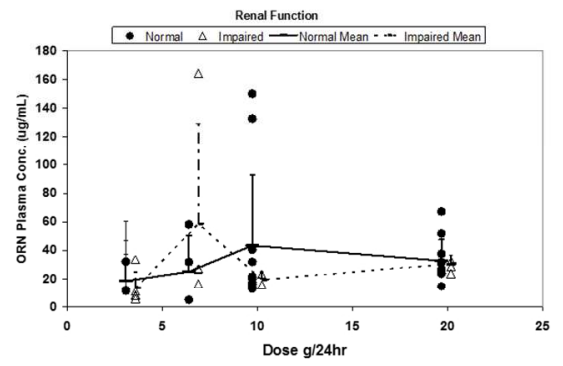

B.
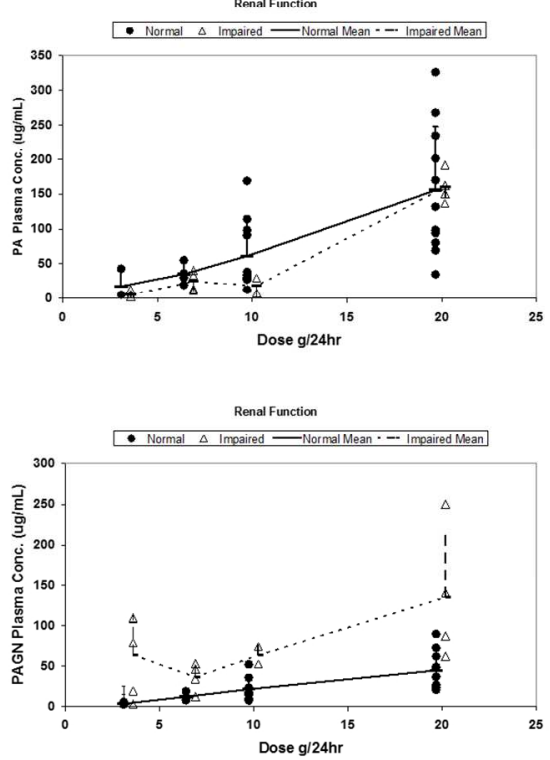

Figure 2

Figure 2

$338 \times 451 \mathrm{~mm}(96 \times 96$ DPI) 
A.

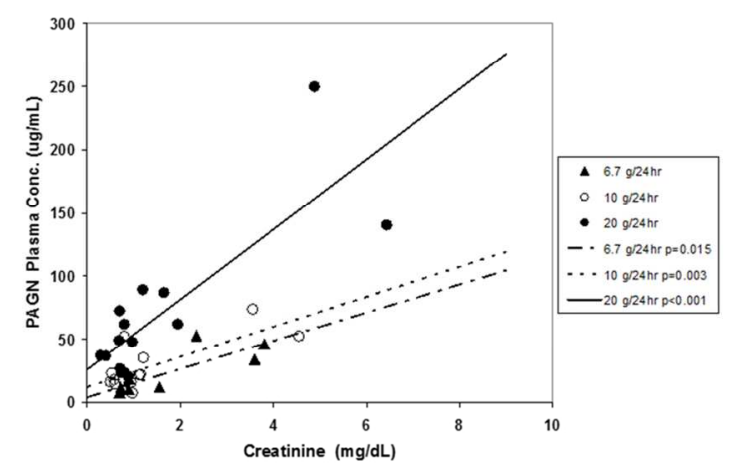

B.

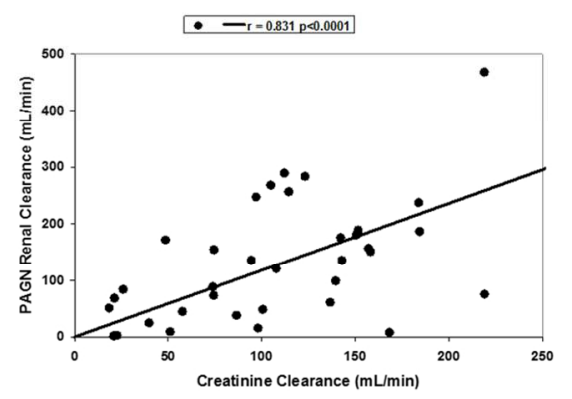

c.

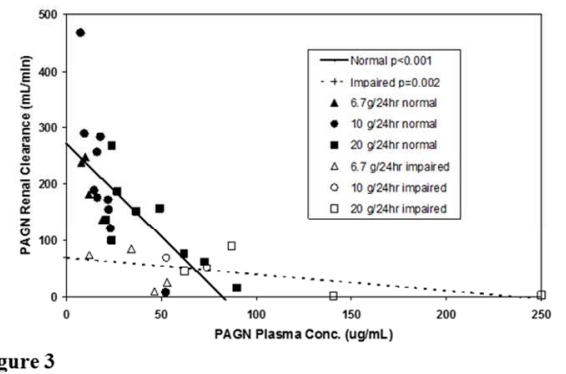

Figure 3

$338 \times 451 \mathrm{~mm}(96 \times 96$ DPI) 


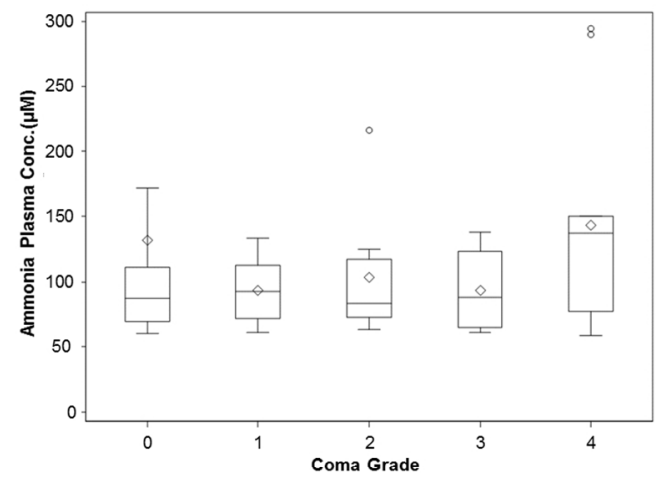

Figure 4

Figure 4 $338 \times 451 \mathrm{~mm}(96 \times 96 \mathrm{DPI})$

Hepatology

This article is protected by copyright. All rights reserved. 


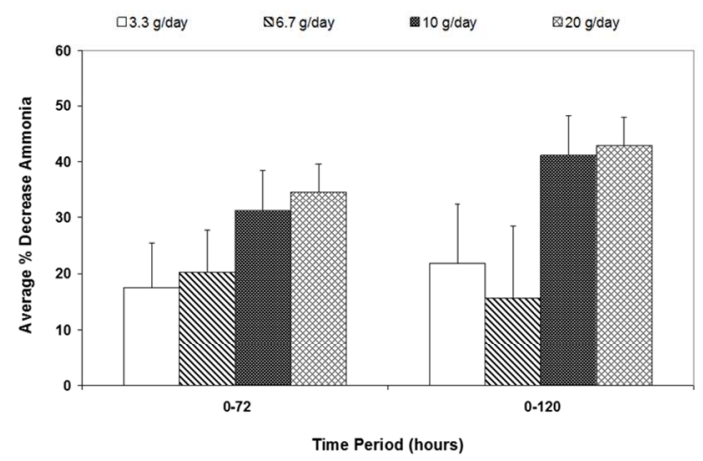

Figure 5

Figure 5 $338 \times 451 \mathrm{~mm}(96 \times 96 \mathrm{DPI})$

Hepatology

This article is protected by copyright. All rights reserved. 


\begin{tabular}{|c|c|c|c|c|c|c|c|c|}
\hline \multirow{3}{*}{ MedDRA Term } & \multicolumn{8}{|c|}{ OPA Dose (g/24h) } \\
\hline & \multicolumn{2}{|c|}{3.3} & \multicolumn{2}{|c|}{6.7} & \multicolumn{2}{|c|}{10} & \multicolumn{2}{|c|}{20} \\
\hline & $\mathbf{N}$ & $\%$ & $\mathbf{N}$ & $\%$ & $\mathbf{N}$ & $\%$ & $\mathbf{N}$ & $\%$ \\
\hline Abdominal distension & 1 & $2.6 \%$ & 0 & $0.0 \%$ & 0 & $0.0 \%$ & 0 & $0.0 \%$ \\
\hline Abdominal pain & 0 & $0.0 \%$ & 0 & $0.0 \%$ & 0 & $0.0 \%$ & 2 & $6.8 \%$ \\
\hline Acute hepatic failure & 1 & $2.6 \%$ & 1 & $6.2 \%$ & 2 & $8.3 \%$ & 0 & $0.0 \%$ \\
\hline Alcohol poisoning & 0 & $0.0 \%$ & 0 & $0.0 \%$ & 1 & $4.1 \%$ & 0 & $0.0 \%$ \\
\hline Alcohol withdrawal syndrome & 0 & $0.0 \%$ & 0 & $0.0 \%$ & 1 & $4.1 \%$ & 0 & $0.0 \%$ \\
\hline Anemia & 1 & $2.6 \%$ & 0 & $0.0 \%$ & 0 & $0.0 \%$ & 0 & $0.0 \%$ \\
\hline Bradycardia & 2 & $5.2 \%$ & 0 & $0.0 \%$ & 0 & $0.0 \%$ & 0 & $0.0 \%$ \\
\hline Brain edema & 0 & $0.0 \%$ & 0 & $0.0 \%$ & 1 & $4.1 \%$ & 0 & $0.0 \%$ \\
\hline Cerebellar infarction & 0 & $0.0 \%$ & 1 & $6.2 \%$ & 0 & $0.0 \%$ & 0 & $0.0 \%$ \\
\hline Circulatory collapse & 1 & $2.6 \%$ & 0 & $0.0 \%$ & 0 & $0.0 \%$ & 0 & $0.0 \%$ \\
\hline Clostridial infection & 0 & $0.0 \%$ & 1 & $6.2 \%$ & 0 & $0.0 \%$ & 0 & $0.0 \%$ \\
\hline Compartment syndrome & 1 & $2.6 \%$ & 0 & $0.0 \%$ & 0 & $0.0 \%$ & 0 & $0.0 \%$ \\
\hline Confusional state & 0 & $0.0 \%$ & 0 & $0.0 \%$ & 1 & $4.1 \%$ & 0 & $0.0 \%$ \\
\hline Constipation & 0 & $0.0 \%$ & 0 & $0.0 \%$ & 3 & $12.5 \%$ & 0 & $0.0 \%$ \\
\hline Cough & 0 & $0.0 \%$ & 0 & $0.0 \%$ & 0 & $0.0 \%$ & 1 & $3.4 \%$ \\
\hline Deep vein thrombosis & 2 & $5.2 \%$ & 0 & $0.0 \%$ & 0 & $0.0 \%$ & 0 & $0.0 \%$ \\
\hline Dyspnea & 0 & $0.0 \%$ & 0 & $0.0 \%$ & 0 & $0.0 \%$ & 1 & $3.4 \%$ \\
\hline Edema & 0 & $0.0 \%$ & 2 & $12.5 \%$ & 0 & $0.0 \%$ & 0 & $0.0 \%$ \\
\hline Edema, peripheral & 1 & $2.6 \%$ & 0 & $0.0 \%$ & 0 & $0.0 \%$ & 0 & $0.0 \%$ \\
\hline Electrocardiogram QT interval & 0 & $0.0 \%$ & 0 & $0.0 \%$ & 1 & $4.1 \%$ & 0 & $0.0 \%$ \\
\hline Electrocardiogram QT prolonged & 1 & $2.6 \%$ & 0 & $0.0 \%$ & 0 & $0.0 \%$ & 1 & $3.4 \%$ \\
\hline Electrocardiogram ST segment elevation & 0 & $0.0 \%$ & 0 & $0.0 \%$ & 0 & $0.0 \%$ & 1 & $3.4 \%$ \\
\hline
\end{tabular}




\begin{tabular}{|c|c|c|c|c|c|c|c|c|}
\hline \multirow{4}{*}{ Headache } & \multicolumn{8}{|c|}{ OPA Dose (g/24h) } \\
\hline & \multicolumn{2}{|c|}{3.3} & \multicolumn{2}{|c|}{6.7} & \multicolumn{2}{|c|}{10} & \multicolumn{2}{|c|}{20} \\
\hline & $\mathbf{N}$ & $\%$ & $\mathbf{N}$ & $\%$ & $\mathbf{N}$ & $\%$ & $\mathbf{N}$ & $\%$ \\
\hline & 1 & $2.6 \%$ & 3 & $18.7 \%$ & 0 & $0.0 \%$ & 0 & $0.0 \%$ \\
\hline Hepatic encephalopathy & 1 & $2.6 \%$ & 0 & $0.0 \%$ & 0 & $0.0 \%$ & 0 & $0.0 \%$ \\
\hline Hypertension & 0 & $0.0 \%$ & 1 & $6.2 \%$ & 0 & $0.0 \%$ & 1 & $3.4 \%$ \\
\hline Hypokalemia & 0 & $0.0 \%$ & 1 & $6.2 \%$ & 1 & $4.1 \%$ & 2 & $6.8 \%$ \\
\hline Hypomagnesemia & 1 & $2.6 \%$ & 0 & $0.0 \%$ & 0 & $0.0 \%$ & 1 & $3.4 \%$ \\
\hline Hypophosphatemia & 0 & $0.0 \%$ & 0 & $0.0 \%$ & 1 & $4.1 \%$ & 2 & $6.8 \%$ \\
\hline Hypotension & 0 & $0.0 \%$ & 0 & $0.0 \%$ & 0 & $0.0 \%$ & 3 & $10.3 \%$ \\
\hline Infusion site pain & 0 & $0.0 \%$ & 1 & $6.2 \%$ & 0 & $0.0 \%$ & 0 & $0.0 \%$ \\
\hline Leukocytosis & 1 & $2.6 \%$ & 0 & $0.0 \%$ & 0 & $0.0 \%$ & 0 & $0.0 \%$ \\
\hline Migraine & 0 & $0.0 \%$ & 0 & $0.0 \%$ & 1 & $4.1 \%$ & 0 & $0.0 \%$ \\
\hline Multi-organ failure & 0 & $0.0 \%$ & 0 & $0.0 \%$ & 0 & $0.0 \%$ & 1 & $3.4 \%$ \\
\hline Nausea & 1 & $2.6 \%$ & 1 & $6.2 \%$ & 1 & $4.1 \%$ & 1 & $3.4 \%$ \\
\hline Neurological decompensation & 0 & $0.0 \%$ & 0 & $0.0 \%$ & 0 & $0.0 \%$ & 1 & $3.4 \%$ \\
\hline Oliguria & 7 & $18.4 \%$ & 0 & $0.0 \%$ & 0 & $0.0 \%$ & 0 & $0.0 \%$ \\
\hline Oropharyngeal pain & 0 & $0.0 \%$ & 0 & $0.0 \%$ & 0 & $0.0 \%$ & 1 & $3.4 \%$ \\
\hline Pelvic pain & 0 & $0.0 \%$ & 0 & $0.0 \%$ & 0 & $0.0 \%$ & 1 & $3.4 \%$ \\
\hline Peritonitis & 0 & $0.0 \%$ & 0 & $0.0 \%$ & 0 & $0.0 \%$ & 1 & $3.4 \%$ \\
\hline Pneumonia & 2 & $5.2 \%$ & 1 & $6.2 \%$ & 1 & $4.1 \%$ & 1 & $3.4 \%$ \\
\hline Pyrexia & 2 & $5.2 \%$ & 1 & $6.2 \%$ & 2 & $8.3 \%$ & 0 & $0.0 \%$ \\
\hline Red man syndrome & 0 & $0.0 \%$ & 0 & $0.0 \%$ & 0 & $0.0 \%$ & 1 & $3.4 \%$ \\
\hline Renal failure acute & 1 & $2.6 \%$ & 0 & $0.0 \%$ & 1 & $4.1 \%$ & 0 & $0.0 \%$ \\
\hline Sepsis & 0 & $0.0 \%$ & 0 & $0.0 \%$ & 0 & $0.0 \%$ & 1 & $3.4 \%$ \\
\hline Septic shock & 0 & $0.0 \%$ & 0 & $0.0 \%$ & 0 & $0.0 \%$ & 1 & $3.4 \%$ \\
\hline
\end{tabular}




\begin{tabular}{|c|c|c|c|c|c|c|c|c|}
\hline \multirow{4}{*}{ MedDRA Term } & \multicolumn{8}{|c|}{ OPA Dose (g/24h) } \\
\hline & \multicolumn{2}{|c|}{3.3} & \multicolumn{2}{|c|}{6.7} & \multicolumn{2}{|c|}{10} & \multicolumn{2}{|c|}{20} \\
\hline & $\mathbf{N}$ & $\%$ & $\mathbf{N}$ & $\%$ & $\mathbf{N}$ & $\%$ & $\mathbf{N}$ & $\%$ \\
\hline & 0 & $0.0 \%$ & 1 & $6.2 \%$ & 0 & $0.0 \%$ & 1 & $3.4 \%$ \\
\hline Subdural hematoma & 0 & $0.0 \%$ & 1 & $6.2 \%$ & 0 & $0.0 \%$ & 0 & $0.0 \%$ \\
\hline Tachycardia & 7 & $18.4 \%$ & 0 & $0.0 \%$ & 0 & $0.0 \%$ & 0 & $0.0 \%$ \\
\hline Tachypnea & 1 & $2.6 \%$ & 0 & $0.0 \%$ & 0 & $0.0 \%$ & 0 & $0.0 \%$ \\
\hline Thrombocytopenia & 0 & $0.0 \%$ & 0 & $0.0 \%$ & 1 & $4.1 \%$ & 0 & $0.0 \%$ \\
\hline Urinary tract infection & 1 & $2.6 \%$ & 0 & $0.0 \%$ & 3 & $12.5 \%$ & 0 & $0.0 \%$ \\
\hline Vision blurred & 1 & $2.6 \%$ & 0 & $0.0 \%$ & 0 & $0.0 \%$ & 0 & $0.0 \%$ \\
\hline Vomiting & 0 & $0.0 \%$ & 0 & $0.0 \%$ & 1 & $4.1 \%$ & 2 & $6.8 \%$ \\
\hline Wheezing & 0 & $0.0 \%$ & 0 & $0.0 \%$ & 0 & $0.0 \%$ & 1 & $3.4 \%$ \\
\hline Wound & 0 & $0.0 \%$ & 0 & $0.0 \%$ & 1 & $4.1 \%$ & 0 & $0.0 \%$ \\
\hline
\end{tabular}




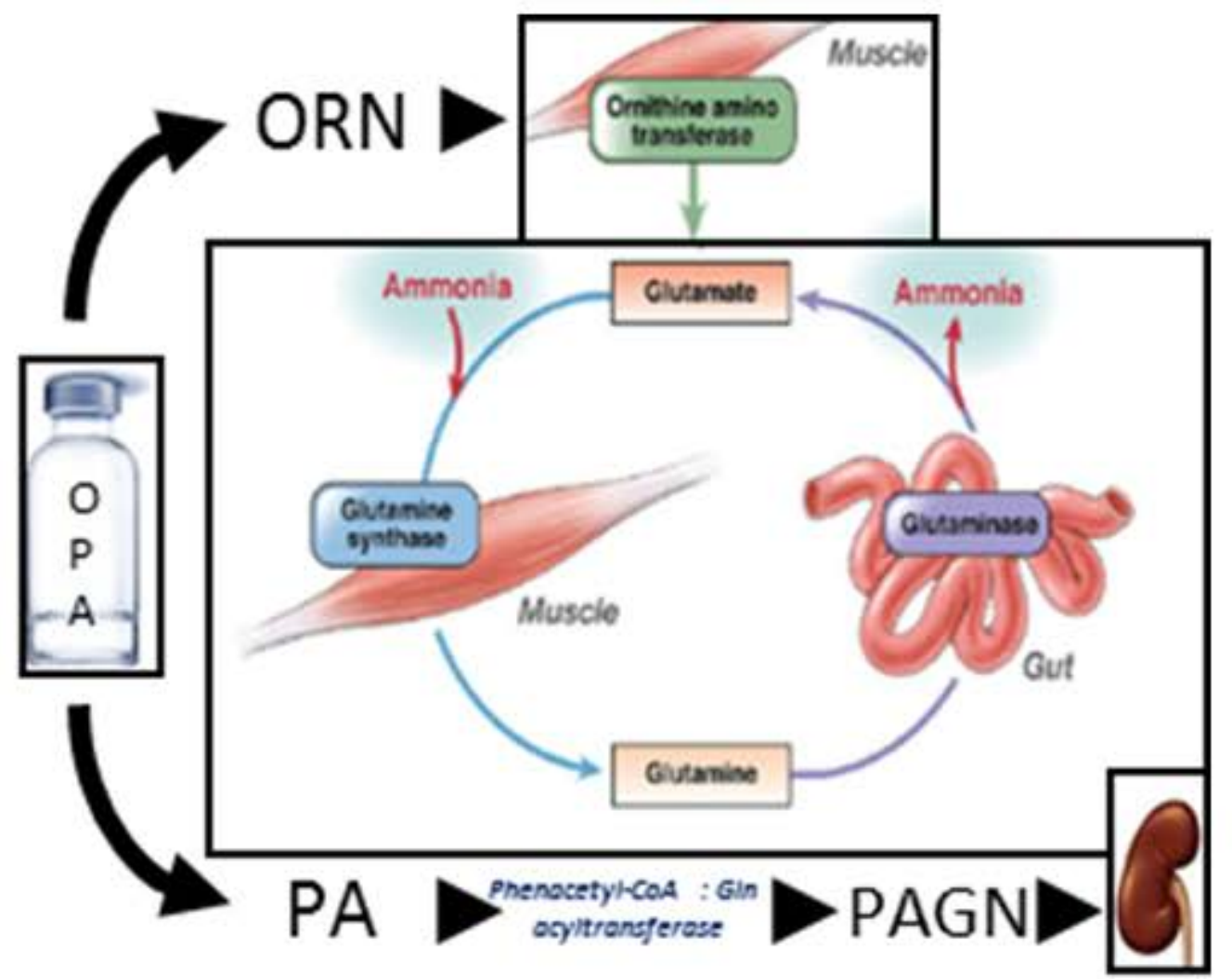

Supplemental Figure 1. Proposed mechanism of ammonia elimination by ornithine phenylacetate. The L-ornithine phenylacetate (OPA) salt dissociates in serum into ornithine (ORN) and phenylacetate (PA). Ornithine is biotransformed into glutamate by muscle ornithine aminotransferase, and ammonia is bound to glutamate by glutamine synthase in muscle to form glutamine. In order to prevent deamidation of glutamine by intestinal glutaminases and release of ammonia, PA is bound to glutamine by phenylacetyl-CoA:glutamine acyltransferase to form phenylacetylglutamine (PAGN), which is renally-excreted. 


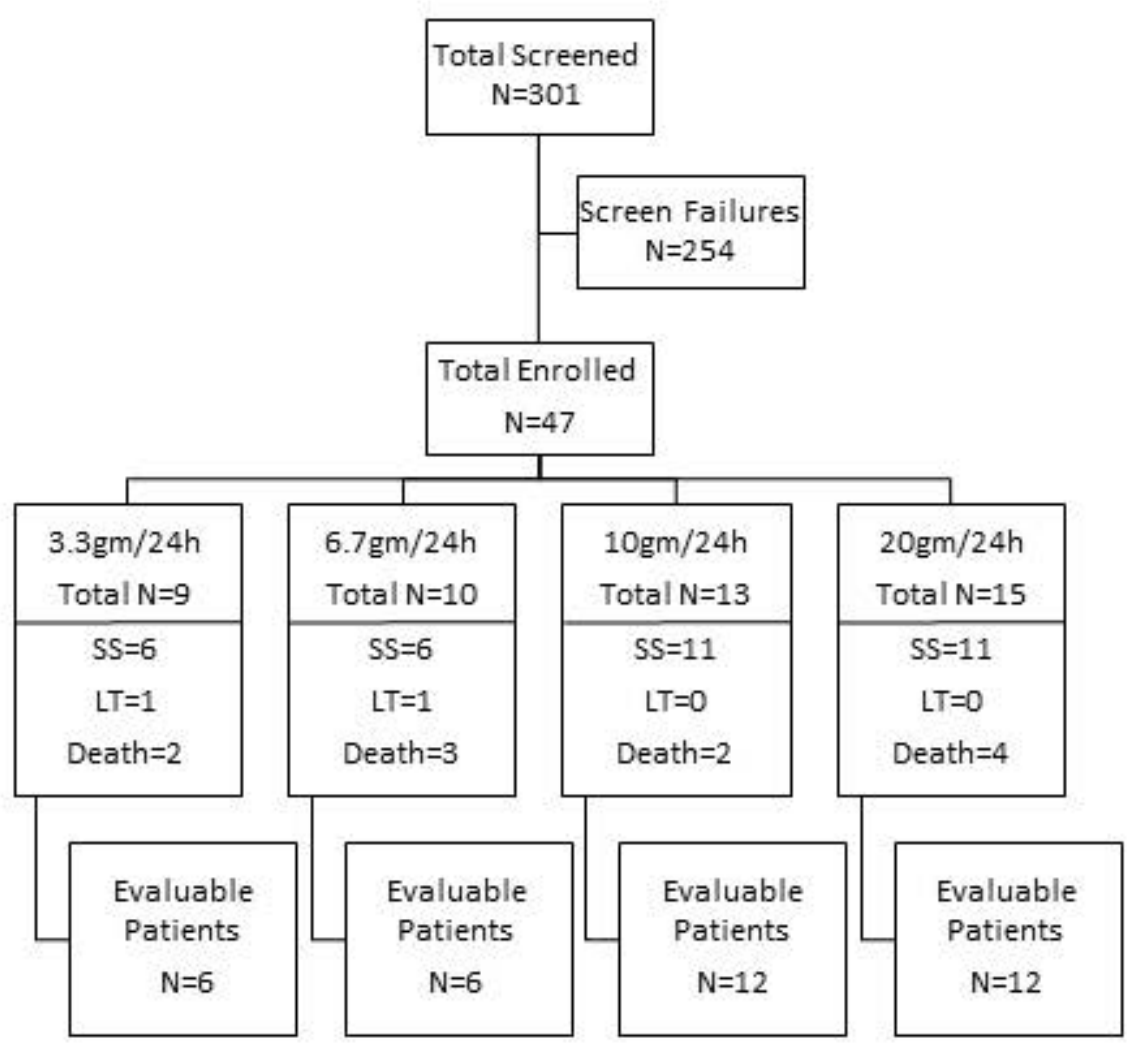

Supplemental Figure 2. Consort diagram of study patients according to the maximal dose infusion of OPA. "Evaluable Patients" are defined as those who received $\geq 72 \mathrm{~h}$ OPA infusion for purposes of evaluating lowering of serum ammonia. The outcomes at 21 days are depicted for each dose level (SS, spontaneous survival; LT, liver transplantation, and death). 


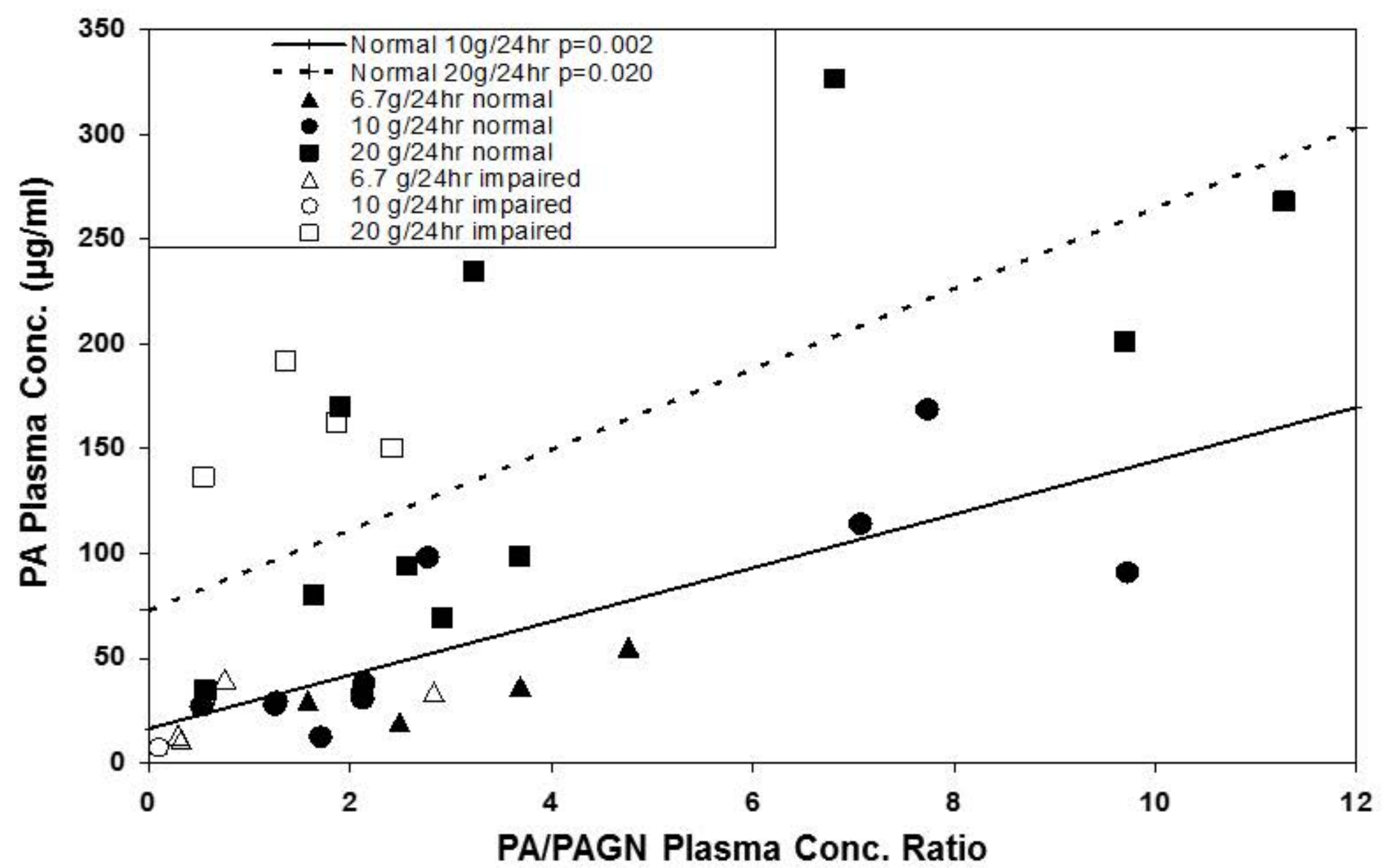

Supplemental Figure 3. Plasma PA vs. plasma PA/PAGN ratio according to dose of OPA in normal and renally-impaired patients with ALI/ALF.

Mokhtarani, et al. (8), have shown in patients with cirrhosis that plasma [PA], the moiety responsible for the neurotoxicity of sodium and glycerol phenylbutryate (precursors of PA) increases as a function of the plasma PA/PAGN ratio, which in turn reflects the biotransformation of PA to PAGN primarily by the liver. As shown, none of the patients with ALI/ALF reached the neurotoxic plasma [PA] of $500 \mu \mathrm{g} / \mathrm{ml}(17,18)$.

$$
\text { Hepatology }
$$

This article is protected by copyright. All rights reserved. 


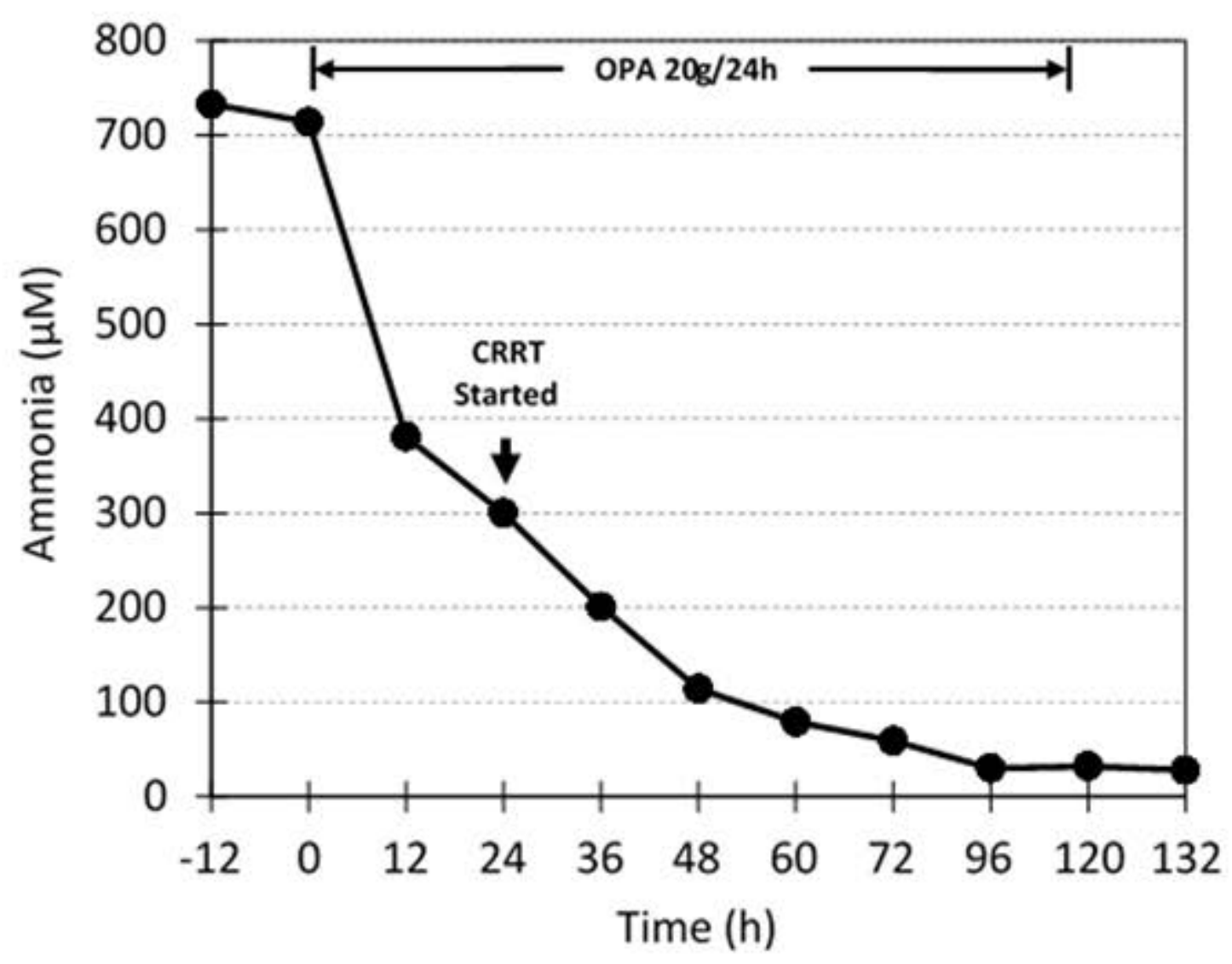

Supplemental Figure 4. Plasma ammonia concentration in a patient with adult Reye's Syndrome prior to, during, and after OPA infusion $(20 \mathrm{~g} / 24 \mathrm{~h})$ and continuous renal replacement therapy (CRRT). 